\title{
İzmir yöresinde yetişen erik, karabiber ve tespih odunlarının statik sertliğinin belirlenmesi üzerine bir araştırma
}

\author{
Ümit Ayata* (D)
}

$\ddot{\mathbf{O} z}$

Ağaçların boylarının ve çaplarının büyümesi birçok farklı çevresel faktörlerden (yetişme yeri, rakım, toprak özellikleri, yıllık yağış miktarı, ağaç türü, ağaç yaşı gibi vb.) etkilenmektedir. Bu faktörlerin etkisi ile ağaçlardan elde edilen odunların teknik özellikleri de değişiklik göstermektedir. Odunun yoğunluğu çevresel faktörlerden etkilenir. Odunun yoğunluğu ve sertlik değeri diğer teknolojik özellikleri hakkında önemli bilgiler vermektedir. Bu çalışmada, İzmir yöresinde yetişen erik (Prunus domestica L.), karabiber (Piper nigrum L.) ve tespih (Melia azedarach L.) ağaç türlerine ait odunlarda statik sertlik değerleri janka yöntemi ve hava kurusu yoğunluklarının belirlenmesi amaçlanmıştır. Ahşap örneklerin janka sertlik değerleri (teğet, radyal ve enine yüzeyler) ve hava kurusu yoğunlukları sirası ile TS 2479 (1976) ve TS 2472 (1976) standartlarına göre belirlenmiştir. Elde edilen veriler SPSS 17 programında istatistiksel olarak değerlendirilmiştir. Araştırma sonuçlarına göre; erik odununda yoğunluk değeri $860.73 \mathrm{~kg} / \mathrm{m}^{3}$ ve karabiber odununda yoğunluk değeri 570.73 $\mathrm{kg} / \mathrm{m}^{3}$ olarak elde edilmiştir. En yüksek janka sertlik değerleri erik odununda elde edilirken, en düşük karabiber odununda izlemiştir.

Anahtar kelimeler: Erik ağac1, karabiber ağacı, tespih ağac1, janka sertlik değeri, odunun yoğunluğu

\section{A study on determination of the static hardness of plum, black pepper and chinaberry woods grown in İzmir region}

\begin{abstract}
The growth of trees' lengths and diameters is influenced by many different environmental factors (growth, altitude, soil characteristics, annual rainfall, tree species, tree age, etc.). With the effect of these factors, the technical properties of the wood obtained from the trees also vary. Wood density is affected by environmental factors. Density and hardness value of wood gives important information about other technological properties. In this study, it was aimed to determine the static hardness values janka method and air densities in woods of the plum (Prunus domestica L.), black pepper (Piper nigrum L.) and chinaberry (Melia azedarach L.) tree species growing in Izmir region. Janka hardness values (tangential, radial and transverse surfaces) and air densities of wood samples were determined according to TS 2479 (1976) and TS 2472 (1976) standards, respectively. The data were evaluated statistically in SPSS 17 program. According to the research results; the density value of the plum wood was $860.73 \mathrm{~kg} / \mathrm{m}^{3}$ and the density value of black pepper wood was $570.73 \mathrm{~kg} / \mathrm{m}^{3}$. The highest janka hardness values were obtained from plum wood, and the lowest hardness values were obtained from black pepper wood.
\end{abstract}

Keywords: Plum tree, black pepper tree, chinaberry tree, janka hardness value, density of wood.

Makale tarihçesi: Geliș:29.05.2019, Kabül:28.11.2019, Yayınlanma:29.12.2019, *Sorumlu yazar: umitayata@bayburt.edu.tr *Bayburt Üniversitesi, Sanat ve Tasarım Fakültesi, İç Mimarlık ve Çevre Tasarımı Bölümü, Bayburt, Türkiye,

Atıf: Ayata, Ü., (2019), İzmir yöresinde yetişen erik, karabiber ve tespih odunlarının statik sertliğinin belirlenmesi üzerine bir araştırma, Mobilya ve Ahşap Malzeme Araştırmaları Dergisi, 2 (2), 94-102. 


\section{Giriş}

Çalışma sırasında alet ve kesicilere gösterdiği dirence ağacın sertliği denir (Şanıvar ve Zorlu 1980). Ahşap sertliği, özellikle zemin ve mobilya endüstrilerinde önemli bir özelliktir. Ahşap malzemenin sertliğini belirlemek için genellikle Brinell ve Janka gibi yöntemler kullanılır. Bu testler, bir çelik yarı kürenin kullanılması ile test edilen yüzeye zorlanacak şekilde gerçekleştirilir (Doyle ve Walker 1984). Janka sertliği, ahşap malzemenin önemli mekanik özelliklerinden biridir. Janka sertlik değeri, bir kerestenin yüzeyindeki çentik kuvvetine dayanma kabiliyetini göstermektedir. Janka sertliği ahşap bir zeminin darbe kuvveti, ezik, sürtünme, çizik, uzun süreli yükleme ve diğer mekanik aşınma ve yıpranmaya devam edip etmeyeceğini göz önünde bulunduran pratik bir yöntemdir (Jamil 2016). Ölçülen değerleri etkileyebilecek bir faktör, yük yönüne göre lifin yönüdür (Holmgren 2000).

Her ağaç türü farklı özellikte janka sertlik değerine sahip olduğundan, ahşap endüstrisi için janka sertlik özelliklerinin belirlenmesi gerekmektedir. Erik, karabiber ve tespih ağaç türleri ülkemizde yetişen ağaç türlerinden olmaktadır. Bu ağaç türleri dünyanın çeşitli yerlerinde farklı ahşap sektöründe (mobilya, marangozluk, v.b.,) kullanılmakta olunup, bu ağaç türlerine ait janka sertlik değerlerinin bilinmesi gerekmektedir. Bu ağaç türleri hakkında kısaca önemli bilgiler vermek gerekirse;

Erik (Prunus domestica L.) ağaç türü, Asya ve Güney Doğu Avrupa'daki en yaygın meyve ağaçları türlerinden biridir (Kiaei ve ark., 2014). Erik bir meyve ağacıdır, düz ve tekil yapraklıdır, kendisine özgü bir kokusu vardır ve sert bir ağaçtır (Dinçel ve ark., 1970). Govorčin ve ark., (2012) tarafindan yapılan çalışmada Prunus domestica L. odununun liflere paralel çekme direnci $44 \mathrm{MPa}$ olarak bulunmuştur. Torna işlerinde ve alet saplarında değerlendirilir. Gövdesi düzgün ve fazla gelişmiş olmadığından elde edilen kaplaması daha çok marketride kullanılır (Dinçel ve diğ., 1970). Resim cetvelleri, resim tahtaları ve nefesli müzik aletleri yapımında kullanılır. Çabuk çürür ve iyi cila tutmaktadır (Hammond ve ark., 1969). Kırılgandır ve rendelenen yüzey parlak bir görünüş verir (Dinçel ve ark., 1970). Kiaei ve ark., (2014) tarafından yapılan araştırmada bu ağaç türüne ait odunların lifleri, yeterli olan kimyasal özellikleri, lif uzunluğu ve yumuşaklık katsayıları nedeniyle kağıt hamuru ve kağıt üretimi için uygun olduğu şeklinde belirtilmiştir.

Karabiber (Piper nigrum L.) ağaç türü, uluslar arası ticareti yapılan en önemli baharattır ve Hindistan, Brezilya, Vietnam, Endonezya, Malezya ve Sri Lanka gibi dünyanın birçok tropik bölgesinde yetiştirilmektedir (Yuen ve ark., 2018). Yapılan bir araştırmada karabiber odununda tam kuru yoğunluk değeri $523.50 \mathrm{~kg} / \mathrm{m}^{3}$, radyal yönde genişleme $\% 3.64$, boyuna yönde genişleme $\% 0.38$, teğet yönde genişleme $\% 7.61$, hacmen genişleme $\% 11.63$, genişleme anizotropisi oran1 2.47, iki hafta sonunda aldığ 1 su miktarı $\% 95.95$, lif doygunluğu noktas1 $\% 22.16$ ve 1sı iletkenlik değeri $0.138 \mathrm{~W} / \mathrm{mK}$ olarak belirlenmiştir (Şahin ve ark., 2019a).

Tespih (Melia azedarach L.) ağaç türü, Hindistan ve Avrupa'nın sıcak bölgelerinde yetişmektedir (Sarıbaş 2016). Optimum koşullar altında hızlı büyümekte olup, sağlam yerlerde dayanıklı ve termitlerden etkilenmeyen iyi özellikte inşaat kerestesi yapmaktadır (URL 2). Tespih odununda yoğunluk değeri $621.67 \mathrm{~kg} / \mathrm{m}^{3}$, ortalama rutubet $\% 13.34$ (Çavuş ve Ayata 2018), tam kuru yoğunluk $\left(D_{0}\right)$ değeri $569.42 \mathrm{~kg} / \mathrm{m}^{3}$, teğet yönde genişleme $\left(\alpha_{t}\right)$ $\% 7.30$, radyal yönde genişleme $\left(\alpha_{\mathrm{r}}\right) \% 4.39$, boyuna yönde genişleme $\left(\alpha_{1}\right) \% 0.17$, lif doygunluğu noktası \%20.79, genişleme anizotropisi oranı 1.67, hacmen genişleme $\left(\alpha_{v}\right)$ \%11.86 ve iki hafta sonunda aldığ 1 su miktarı \%57.39 olarak belirlenmiştir (Şahin ve ark., 2019 b). Yoğunluğu 510-660 kg/m³ tohumun ağırlığı 75-250 g'dır (URL 1). Tespih odununda teğet yüzeyde vida tutma direnci 
$35.66 \mathrm{~N} / \mathrm{mm}^{2}$, radyal yüzeyde vida tutma direnci $30.31 \mathrm{~N} / \mathrm{mm}^{2}$ ve enine yüzeyde vida tutma direnci $24.02 \mathrm{~N} / \mathrm{mm}^{2}$ (Çavuş ve Ayata 2018) ve 1sı iletkenlik değeri $0.147 \mathrm{~W} / \mathrm{mK}$ (Şahin ve ark., 2019b) olarak belirlenmiştir. Bu ağaç termit dayanıklılı̆̆ arabaları, alet kolları, mobilya yapımında ve inşaatlarda (URL 1) mutfak dolapları, ambalaj kutuları, ofis mobilyaları, salon takımları, çekmece tarafları, fiçılar, sandalyeler, sandıklar ve takunya yapımda (URL 2) değerlendirilmektedir. Ayrıca meyvesi zehirli olup, kabukları ateş düşürücü olarak kullanılmaktadır (Sarıbaş 2016). Bu bilgiler ışığında İzmir'de yetişen bu ağaç türlerine daha önce statik sertlik özelliğinin araştırılmadığı belirlenmiştir.

$\mathrm{Bu}$ çalışmada, İzmir yöresinde yetişen tespih (Melia azedarach L.), erik (Prunus domestica L.) ve karabiber (Piper nigrum L.) ağaç türlerine ait odunlar üzerinde janka yöntemine göre statik sertlik değerleri ve erik ile karabiber türlerinde yoğunluk değerleri araştırılmıştır. Elde edilen bu sonuçların bu ağaç türlerine ait literatür bilgisine önemli katkı sağlayacağı söylenebilir.

\section{Materyal ve Metot}

\subsection{Materyal}

$\mathrm{Bu}$ çalışmada, test örneklerinin hazırlanmasında erik (Prunus domestica L.), karabiber (Piper nigrum L.) ve tespih (Melia azedarach L.) ağaçlarının odunları kullanılmıştır. Deneme materyalleri İzmir ilinde bulunan bir keresteciden satın alma yöntemi ile alınmıştır.

\subsection{Metot}

\subsubsection{Hava kurusu yoğunluk değerinin belirlenmesi}

$\mathrm{Bu}$ çalışmada, erik ve karabiber test örneklerinin yoğunlukları, test örneğinin tamamı üzerinde belirlenmiştir. Yoğunluk belirlemede TS 2472 (1976) numaralı standartta belirtilen esaslara uyulmuştur. Erik ve karabiber odunlarına ait hava kurusu yoğunluk değerleri aşağıdaki formül (1) ile hesaplanmıştır.

$$
\mathrm{D}_{12}=\mathrm{M}_{12} / \mathrm{V}_{12}\left(\mathrm{~kg} / \mathrm{m}^{3}\right)
$$

Burada;

$\mathrm{D}_{12}$ : Hava kurusu yoğunluk $\left(\mathrm{kg} / \mathrm{m}^{3}\right)$,

$\mathrm{M}_{12}$ : Hava kurusu ağırlık $(\mathrm{kg})$,

$\mathrm{V}_{12}$ : Hava kurusu hacimdir $\left(\mathrm{m}^{3}\right)$.

\subsubsection{Statik sertlik değerinin belirlenmesi}

Statik sertlik denemeleri TS 2479 (1976) numaralı standarda göre belirlenmiştir. Bu standarda göre; erik, karabiber ve tespih odunları için test örnekleri, kenarları 50 x 50 x 50 $\mathrm{mm}$ olan küp biçiminde hazırlanmıştır. Denemeler radyal, teğet ve enine kesitlerde, yapılmıştır. 3-6 mm/dk hızla hareket eden yükleme ucu ile deney parçasının radyal, teğet ve enine kesit yüzeylerinin merkez eksenleri üzerinde yarım küre ucun yarıçapına (5.64 mm) eşit olan derinlikte bir oyuk açılmıştır. Bu derinliğe ulaşıldığ 1 andaki yük \%1 duyarlıkta okunmuştur. Her bir deney parçasının statik sertliği $\mathrm{H}_{\mathrm{j}}$ deneyin yapıldığı rutubet miktarında alanı $1 \mathrm{~cm}^{2}$,ye eşit olan bir iz elde edebilmek için gerekli yük miktarı (Newton) olarak aşağıdaki formülle (2) hesaplanmıştır.

$$
\mathrm{Hj}=\mathrm{K} \times \mathrm{P}_{\max } \quad\left(\mathrm{N} / \mathrm{mm}^{2}\right)
$$


Burada: $P_{\max }$ : yükleme ucunun deney parçasının içersinde belirli derinliğe girmesi sırasındaki yük $\mathrm{N}$ olarak, K: yükleme ucunun $5.64 \mathrm{~mm}$ derinliğe girmesi halinde 1'e, $2.82 \mathrm{~mm}$ derinliğe girmesi halinde ise $4 / 3$ 'e eşit olan bir katsayıdır.

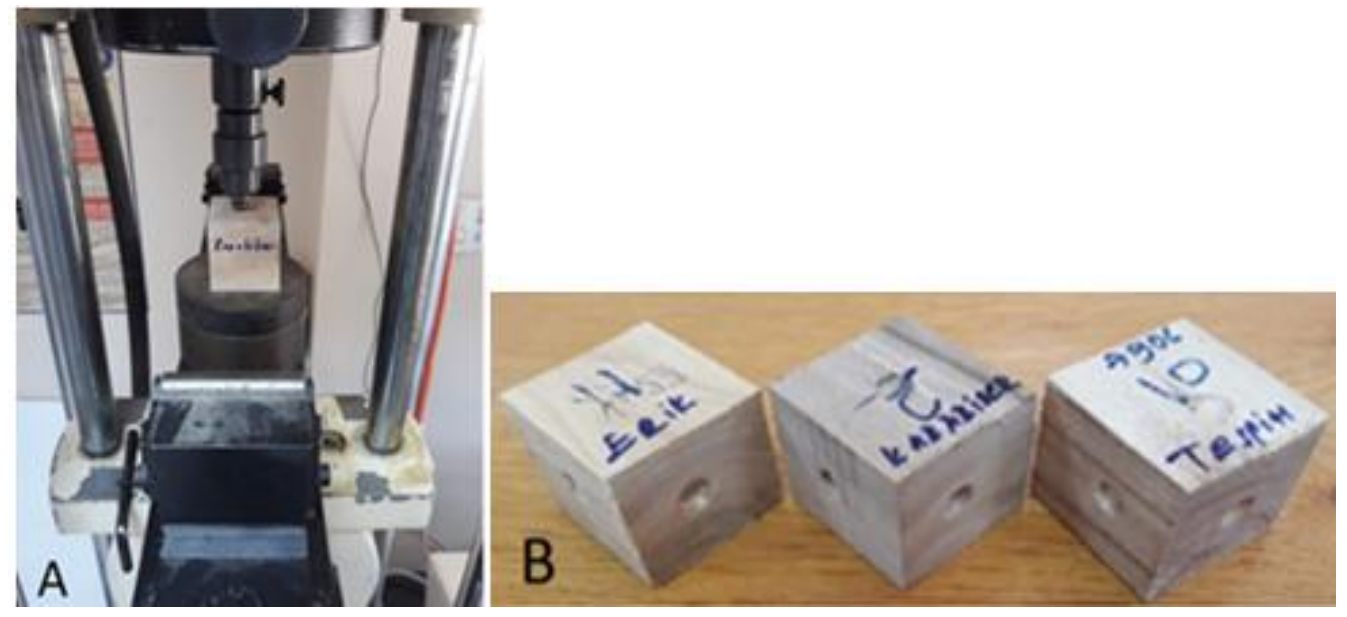

Şekil 1. Janka statik sertlik testinin yapılışı esnasındaki görüntüsü (A) ve janka testi sonrası test örneklerinin görüntüsü (B)

\section{3. İstatistik Hesaplarının Yapılması}

Çalışmada kullanılan erik, karabiber ve tespih ağaç türlerine ait odun numuneleri üzerinde yapılan janka testine (radyal, teğet ve enine yüzeyler) ait veriler kullanılarak SPSS 17 (Sun Microsystems, Inc., Santa Clara, CA, USA) programı ile varyans analizleri, ortalamaları, standart sapmaları, homojenlik grupları, minimum değerleri, maksimum değerleri ve varyasyon katsayıları hesaplanmış olunup, bu sonuçlar tablolar halinde verilmiştir.

\section{Bulgular ve Tartışma}

Erik ve karabiber ağaç türlerine ait deney numunelerinde belirlenen hava kurusu yoğunluk değerlerine ait sonuçları, homojenlik grupları, standart sapmaları, minimum ve maksimum değerleri, varyasyon katsayıları ve örnek sayısına ilişkin verileri Tablo 1'de gösterilmiştir. Elde edilen bu sonuçlara göre; erik odununda yoğunluk değeri $860.73 \mathrm{~kg} / \mathrm{m}^{3}$ ve karabiber odununda yoğunluk değeri $570.73 \mathrm{~kg} / \mathrm{m}^{3}$ olarak belirlenmiştir (Tablo 1). Ayrıca Çavuş ve Ayata (2018) tarafindan yapılan çalışmada tespih odununda yoğunluk değeri 621.67 $\mathrm{kg} / \mathrm{m}^{3}$ olarak belirlenmiştir.

Tablo 1. Erik ve karabiber ağaç türlerine ait deney numuneleri üzerinde belirlenmiş olan hava kurusu yoğunluk $\left(\mathrm{kg} / \mathrm{m}^{3}\right)$ değerlerine ait sonuçlar

\begin{tabular}{|c|c|c|c|c|c|c|c|}
\hline Ağaç Türü (Latince adı) & $\mathbf{N}$ & $X$ & $S S$ & $H G$ & Minimum & Maksimum & Varyasyon Katsayısı \\
\hline $\begin{array}{c}\text { Erik ağacı } \\
\text { (Prunus domestica } \text { L.) }\end{array}$ & 15 & 860.73 & 16.43 & $A^{*}$ & 827.00 & 883.00 & 1.92 \\
\hline $\begin{array}{c}\text { Karabiber Ăgacı } \\
\text { (Piper nigrum L.) }\end{array}$ & 15 & 570.73 & 22.87 & $\mathrm{~B} * *$ & 530.00 & 615.00 & 4.01 \\
\hline
\end{tabular}

N: Ölçüm Sayısı, $X$ : Ortalamalar, SS: Standart Sapma, HG: Homojenlik Grubu, *: En yüksek değeri ifade etmektedir, **: En düşük değeri ifade etmektedir.

Erik, karabiber ve tespih ağaç türlerine ait odunlar üzerinde yapılan janka sertlik testlerine ait varyans analizi sonuçları Tablo 2'de verilmiştir. Belirlenmiş olan bu janka sertlik 
testleri için ağaç türü (A) ve test yüzey yönü (B) faktörleri anlamlı olarak belirlenirken, bu faktörlerin etkileşimi (AB) anlamsız olarak elde edilmiştir (Tablo 2).

Tablo 2. Erik, karabiber ve tespih ağaç türlerine ait belirlenen janka sertlik testlerine ait varyans analizi sonuçları

\begin{tabular}{|c|c|c|c|c|c|}
\hline Varyans Kaynağı & Kareler Toplamı & Serbestlik Derecesi & Ortalama Kare & F Değeri & $\boldsymbol{\alpha} \leq \mathbf{0 . 0 5}$ \\
\hline A ğaç Türü (A) & 93988.428 & 2 & 46994.214 & 673.257 & $0.000^{*}$ \\
\hline Test Yüzeyi (B) & 7856.534 & 2 & 3928.267 & 56.278 & $0.000^{*}$ \\
\hline Etkileşim (AB) & 594.768 & 4 & 148.692 & 2.130 & $0.081^{* *}$ \\
\hline Hata & 8794.959 & 126 & 69.801 & & \\
\hline Toplam & 847212.740 & 135 & & & \\
\hline \multicolumn{7}{|c}{ *: Anlaml, ***: Anlamsız } \\
\hline
\end{tabular}

Erik, karabiber ve tespih ağaç türlerine ait belirlenen janka sertlik testlerine ait sonuçlar ile standart sapma, homojenlik grubu, minimum ve maksimum değerler, varyasyon katsayıları ve örnek sayısına ilişkin veriler Tablo 3'de ve bu sonuçlara ait grafik Şekil 2'de gösterilmektedir.

Tablo 3. Erik, karabiber ve tespih ağaç türlerine ait deney numunelerinde belirlenen janka sertlik $\left(\mathrm{N} / \mathrm{mm}^{2}\right)$ testlerine ait sonuçlar

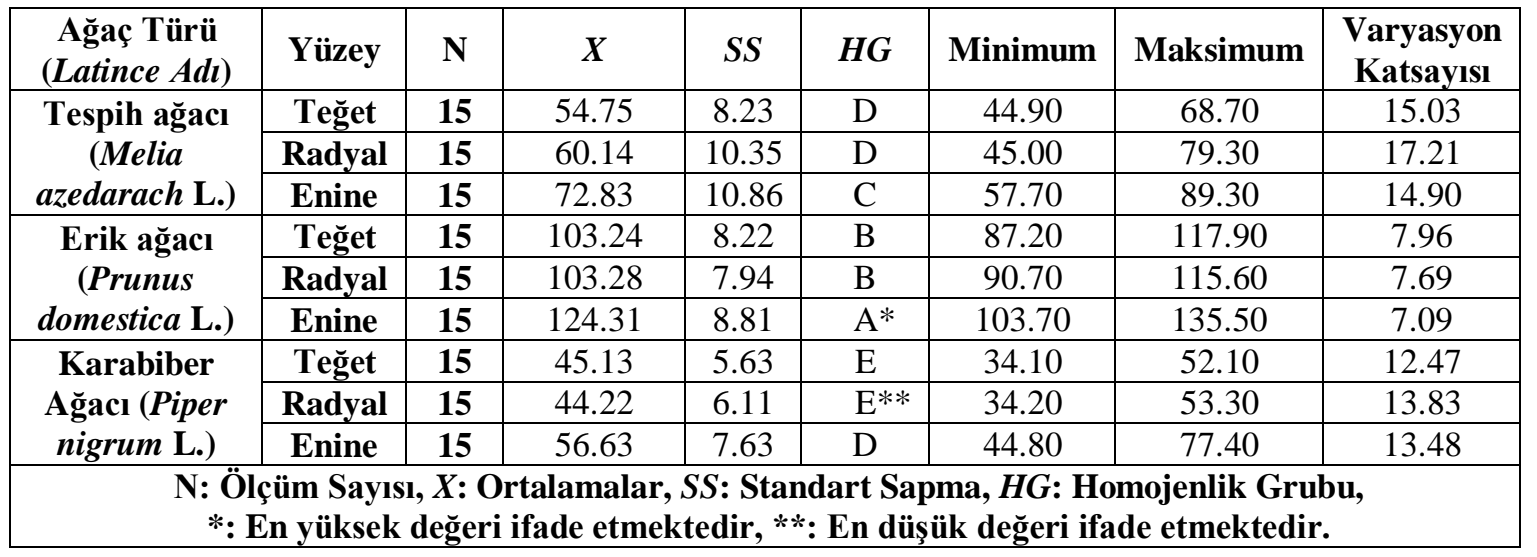

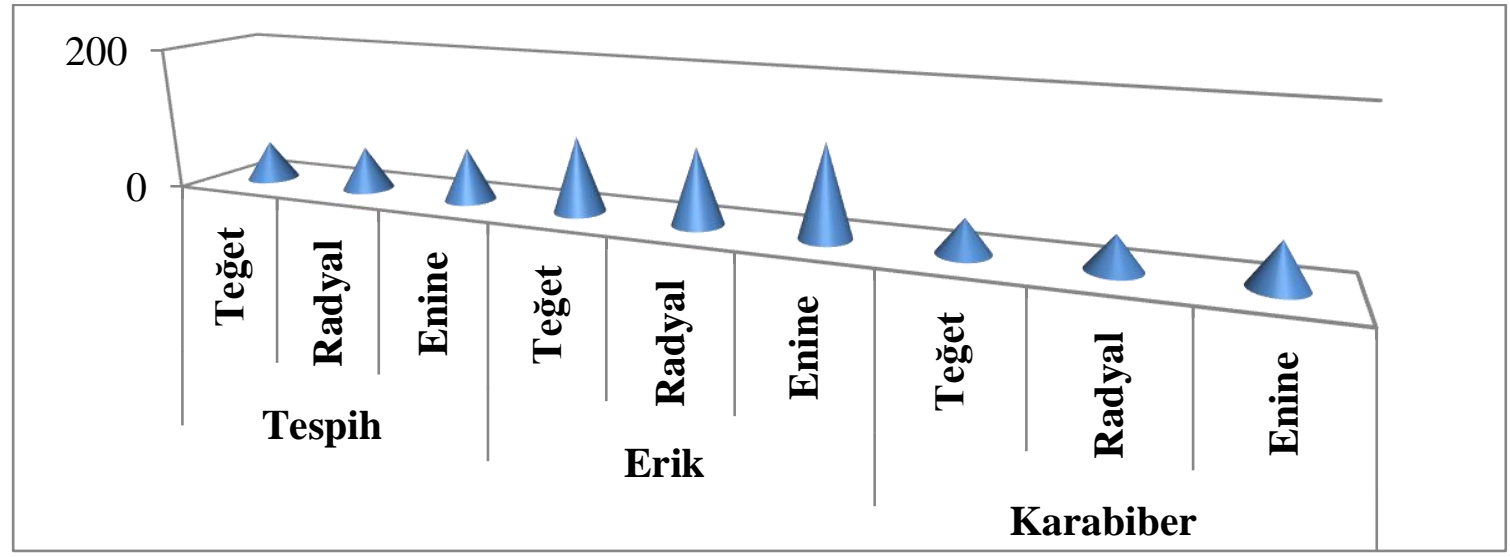

Şekil 2. Erik, karabiber ve tespih ağaç türlerine ait janka sertlik testi sonuçları $\left(\mathrm{N} / \mathrm{mm}^{2}\right)$

Tespih ağacında janka sertlik değeri teğet, radyal ve enine yüzeyler için sırası ile 54.75 $\mathrm{N} / \mathrm{mm}^{2}, 60.14 \mathrm{~N} / \mathrm{mm}^{2}$ ve $72.83 \mathrm{~N} / \mathrm{mm}^{2}$ olarak, erik ağacında janka sertlik değeri teğet, radyal ve enine yüzeyler için sırası ile $103.24 \mathrm{~N} / \mathrm{mm}^{2}, 103.28 \mathrm{~N} / \mathrm{mm}^{2}$ ve $124.31 \mathrm{~N} / \mathrm{mm}^{2}$ olarak tespit 
edilirken, karabiber ağacında janka sertlik değeri teğet, radyal ve enine yüzeyler için sırası ile $45.13 \mathrm{~N} / \mathrm{mm}^{2}, 44.22 \mathrm{~N} / \mathrm{mm}^{2}$ ve $56.63 \mathrm{~N} / \mathrm{mm}^{2}$ olarak olarak elde edilmiştir (Tablo 3). Bazı ağaç türlerinde belirlenmiş olan janka sertlik değerleri ve bu çalışmada kullanılan türler ile kıyaslanması Tablo 4'de verilmiştir.

Tablo 4. Bazı ağaç türlerinde belirlenmiş olan janka sertlik değeri ve bu çalışmada kullanılan türler ile kıyaslanması

\begin{tabular}{|c|c|c|c|c|}
\hline \multirow[b]{2}{*}{$\begin{array}{c}\text { Ăgaç Türü } \\
\text { (Latince Adt) }\end{array}$} & \multicolumn{3}{|c|}{ Janka Sertlik Değeri $\left(\mathrm{N} / \mathbf{m m}^{2}\right)$} & \multirow[b]{2}{*}{ Kaynak } \\
\hline & $\begin{array}{l}\text { Teğet } \\
\text { Yüzey }\end{array}$ & $\begin{array}{c}\text { Radyal } \\
\text { Yüzey }\end{array}$ & $\begin{array}{l}\text { Enine } \\
\text { Yüzey }\end{array}$ & \\
\hline Pavlonya (Paulownia elongata) & 10.81 & 10.48 & 19.81 & Bektaş ve diğ., (2012) \\
\hline Yabani kiraz (Cerasus avium (L.) Monench) & 12.26 & 13.76 & 26.34 & Aytin (2013) \\
\hline Sarıçam (Pinus sylvestris L.) & 15.70 & 15.90 & 23.70 & Bal ve Akçakaya (2016) \\
\hline Duglas (Pseudotsuga menziesii (Mirb.) Franco) & 24.68 & 21.82 & 36.17 & Ay $(2005)$ \\
\hline Sedir (Cedrus libani A. Richard) & 27.21 & 27.45 & 54.38 & Ayata ve diğ., (2018) \\
\hline Kızılağaç (Alnus barhata C. A. Mey) & 28.07 & 25.79 & 39.83 & Ayata ve Bal (2019e) \\
\hline Toros sediri (Cedrus libani A. Richard) genç o. & 28.70 & 26.40 & 49.20 & Bal ve diğ., (2012) \\
\hline Toros sediri (Cedrus libani A. Richard) olgun o. & 30.50 & 31.10 & 53.60 & Bal ve diğ., (2012) \\
\hline Ceviz (Juglans regia L.) & 37.00 & 39.30 & 59.29 & Kantay ve diğ., (2000) \\
\hline İğde (Elaeagnus angustifolia L.) & 40.23 & 40.10 & 58.74 & Ayata ve Bal (2019a) \\
\hline Kızılçam (Pinus brutia Ten.) & 42.39 & 40.99 & 61.86 & Ayata ve diğ., (2018) \\
\hline Karabiber (Piper nigrum L.) ağacı & 45.13 & 44.22 & 56.63 & Tespit \\
\hline Doğu çınarı (Platanus orientalis L.) & 45.87 & 41.22 & 62.63 & Ayata ve diğ., (2018) \\
\hline Hus $($ Betula pendula $)$ & 52.80 & 46.60 & 62.50 & Bal ve diğ., (2018) \\
\hline Istranca meșesi (Quercus hartwissiana) & 54.90 & 58.30 & 78.00 & Dündar (1997) \\
\hline Tespih (Melia azedarach L.) & 54.75 & 60.14 & 72.83 & Tespit \\
\hline Sapsiz mese (Quercus petreae L.) & 62.59 & 57.42 & 69.87 & Ayata ve Bal (2019b) \\
\hline Yalanc1 akasya (Robinia pseudoacacia $\mathrm{L}$.) & 65.09 & 74.07 & 80.46 & Ayata ve Bal (2019d) \\
\hline Dut (Morus Sp.) & 77.69 & 73.24 & 93.71 & Ayata ve diğ., (2018) \\
\hline Harnup (Ceratonia siliqua L.) & 85.15 & 91.50 & 109.83 & Göker ve diğ., (1999) \\
\hline Amerikan ceviz (Juglans nigra L.) & 89.38 & 85.53 & 101.94 & Ayata ve Bal (2019c) \\
\hline Turunç (Citrus aurantium L.) & 80.09 & 76.48 & 82.25 & Ayata ve diğ., (2019) \\
\hline Dişbudak (Fraxinus angustifolia Vahl.) & 70.88 & 66.63 & 105.86 & Şahin (2013) \\
\hline Mazı meșesi (Quercus infectoria oliv) & 97.10 & 95.85 & 105.73 & Rajab (2014) \\
\hline Erik (Prunus domestica L.) & 103.24 & 103.28 & 124.31 & Tespit \\
\hline
\end{tabular}

Çalışmada kullanılan bütün ağaç türlerinde belirlenmiş olan enine yüzeylere ait janka sertlik değerleri, radyal ve teğet yüzeylere ait janka sertlik değerlerinden yüksek elde edilmiştir. Dündar (1997) tarafindan Istranca meşesi (Quercus hartwissiana), Bal ve Akçakaya (2016) tarafından sarıçam, Bal ve ark., (2012) tarafından Toros sediri (Cedrus libani A. Richard)'nin genç ve olgun odun kısımları, Bektaş ve ark., (2012) tarafindan pavlonya (Paulownia elongata), Aytin (2013) tarafindan yabani kiraz (Cerasus avium (L.) Monench), Şahin (2013) doğal meşcereden alınan dişbudak (Fraxinus angustifolia Vahl.), Ayata ve ark., (2018) tarafindan sedir (Cedrus libani A. Richard), dut (Morus Sp.), kızılçam (Pinus brutia Ten.), doğu çınarı (Platanus orientalis L.), Bal ve ark., (2018) tarafından huş (Betula pendula), Rajab (2014) tarafindan mazı meşesi (Quercus infectoria oliv), Ayata ve Bal (2019a) tarafindan iğde (Elaeagnus angustifolia L.), Ayata ve Bal (2019b) tarafindan sapsiz meşe (Quercus petreae L.), Ayata ve Bal (2019c) tarafindan Amerikan ceviz (Juglans nigra L.), Ayata ve Bal (2019d) tarafindan yalanc1 akasya (Robinia pseudoacacia L.), Ayata ve Bal (2019e) tarafindan kızılağaç (Alnus barhata C. A. Mey), Göker ve ark., (1999) tarafindan harnup (Ceratonia siliqua L.), Ay (2005) tarafindan Duglas (Pseudotsuga 
menziesii (Mirb.) Franco), Kantay ve ark., (2000) tarafindan ceviz (Juglans regia L.) ve Ayata ve ark., (2019) tarafindan turunç (Citrus aurantium L.) odunu türlerinde belirlenmiş olan janka sertlik testleri için enine yüzeylerde yapılan janka sertlik değerinin diğer yüzeylere göre yüksek sonuçlar verdiği şeklinde bildirilmiştir (Tablo 4). Bunun sebebi olarak, odun hücrelerinin çoğunluğunun boyuna yönde uzanmasından kaynaklandığı şeklinde bildirilmiştir (Ayata ve ark., 2018). Literatürde ölçülen değerleri etkileyebilecek bir faktör, yük yönüne göre lifin yönü olduğu şeklinde bildirilmiştir (Holmgren 2000). Ayrıca literatürde sertliğin ağaçtan ağaca büyük farklar gösterdiği de ifade edilmiştir (Şanıvar ve Zorlu 1980). Çalışma bulguları, literatür ile uyumlu sonuçlar vermiştir.

\section{Sonuçlar ve Öneriler}

$\mathrm{Bu}$ araştırmada İzmir yöresinde yetişen karabiber (Piper nigrum L.), erik (Prunus domestica L.) ve tespih (Melia azedarach L.) odunlarında statik sertlik değerleri janka yöntemi ve erik ve karabiber odunlarında hava kurusu yoğunlukları araştırılmıştır. Araştırma sonuçlarına göre;

- Erik odununda ortalama yoğunluk değeri $860.73 \mathrm{~kg} / \mathrm{m}^{3}$ ve karabiber odununda ortalama yoğunluk değeri $570.73 \mathrm{~kg} / \mathrm{m}^{3}$ olarak tespit edilmiştir.

- Janka sertlik değeri teğet yüzeyde tespih, erik ve karabiber ağaçlarında sırası ile 54.75 $\mathrm{N} / \mathrm{mm}^{2}, 103.24 \mathrm{~N} / \mathrm{mm}^{2}, 45.13 \mathrm{~N} / \mathrm{mm}^{2}$, radyal yüzeylerde aynı ağaç sırası ile 60.14 $\mathrm{N} / \mathrm{mm}^{2}, 103.28 \mathrm{~N} / \mathrm{mm}^{2}, 44.22 \mathrm{~N} / \mathrm{mm}^{2}$ ve enine yüzeylerde aynı ağaç sırası ile 72.83 $\mathrm{N} / \mathrm{mm}^{2}, 124.31 \mathrm{~N} / \mathrm{mm}^{2}$ ve $56.63 \mathrm{~N} / \mathrm{mm}^{2}$ olarak elde edilmiştir.

- Bütün ağaç türlerinde enine yüzeylere ait janka sertlik değerleri, radyal ve teğet yüzeylere ait janka sertlik değerlerinden yüksek belirlenmiştir.

\section{Teşekkür}

Bu çalışma kapsamındaki laboratuar çalışmalarında, testlerin yapılmasında emeği geçen Doç. Dr. Bekir Cihad BAL'a ve ahşap malzemelerin temin edilmesinde yardımlarını esirgemeyen Dr. Öğretim Üyesi Vedat ÇAVUŞ’a teşekkür ederim.

\section{Kaynaklar}

Ay, N., (2005), Duglas (Pseudotsuga menziesii (Mirb.) Franco) odununun janka sertlik değeri, Kafkas Üniversitesi Artvin Orman Fakültesi Dergisi, 6 (1-2), 11-16.

Ayata, Ü., Çavuş, V., Bal, B.C., Efe, F.T., (2018), Dut, doğu çınarı, kızılçam ve sedir ağaç türlerinde janka sertlik değerinin belirlenmesi, 2. Uluslararası Bilimsel Çalışmalarda Yenilikçi Yaklaşımlar Sempozyumu, 30 Kasım - 2 Aralık, Samsun, Türkiye, 14901494.

Ayata, Ü., Bal, B.C., (2019a), İzmir'de yetişen iğde (Elaeagnus angustifolia L.) odununda bazı fiziksel ve mekanik özelliklerinin belirlenmesi, Bartın Orman Fakültesi Dergisi, 21(3), 751-757. DOI: 10.24011/barofd.589247.

Ayata, Ü., Bal, B.C., (2019b), Sapsız meşe (Quercus petreae L.) odununda statik sertlik tayini ve yüzey pürüzlülüğü parametreleri, ISPEC 2. Uluslararası Tarım ve Kırsal Kalkınma Kongresi, 27 - 29 Eylül, Kiev, Ukrayna, 22-28.

Ayata, Ü., Bal, B.C., (2019c), Amerikan ceviz odununda yüzey pürüzlülüğü, janka sertlik değeri ve çivi tutma direncinin belirlenmesi, Çukurova 3. Uluslararası Yenilikçi Bilimsel Araştırmalar Kongresi, 3 - 6 Ekim, Adana, Türkiye, 440-448. 
Ayata, Ü., Bal, B.C., (2019d), Yalancı akasya odununda çivi tutma direnci ve janka sertlik değerinin belirlenmesi, III. Uluslararası Akdeniz Orman ve Çevre Sempozyumu, 3 - 5 Ekim, Kahramanmaraş, Türkiye, 927-931.

Ayata, Ü., Bal, B.C., (2019e), Kızılağaç odununda statik sertlik, yüzey pürüzlülüğü ve çivi tutma direncinin belirlenmesi, III. Uluslararası Akdeniz Orman ve Çevre Sempozyumu, 3-5 Ekim, Kahramanmaraş, Türkiye, 921-926.

Ayata, Ü., Bal, B.C., Şahin, S., (2019), Turunç odununda 1sı iletkenlik değeri, statik sertlik ve çivi tutma direncinin belirlenmesi, Çukurova 3. Uluslararası Yenilikçi Bilimsel Araştırmalar Kongresi, 3 - 6 Ekim, Adana, Türkiye, 423-430.

Aytin, A., (2013), Yabani kiraz (Cerasus avium (L.) Monench) odununun fiziksel, mekanik ve teknolojik özellikleri üzerine yüksek sicaklık uygulamasının etkisi, Düzce Üniversitesi, Fen Bilimleri Enstitüsü, Orman Endüstri Mühendisliği Anabilim Dall, Doktora Tezi, Düzce.

Bal, B.C., Akçakaya, E., (2016), Isıl işlem görmüş çam odunun bazı fiziksel özellikleri ve sertlik değerleri, 1st International Mediterranean Science and Engineering Congress (IMSEC 2016), October 26-28, 2016, Adana, Turkey.

Bal, B.C., Bektaş, İ., Kaymakçı, A., (2012), Toros sedirinde genç odun ve olgun odunun bazı fiziksel ve mekanik özellikleri, KSU Mühendislik Bilimleri Dergisi, 15(2), 17-27.

Bal, B.C., Ayata, Ü., Çavuş, V., Şahin, S., Efe, F.T., Dilik, T., (2018), Huş (Betula pendula) odununun bazı fiziksel ve mekanik özelliklerinin araştırılması, IV. Uluslararası Mesleki ve Teknik Bilimler Kongresi (UMTEB), 7-9 Aralık, Erzurum, Türkiye, 2104-2113.

Bektaş, İ., Kaymakçı, A., Bal, B.C., (2012), Kahramanmaraş bölgesinde yetiştirilen pavlonya (Paulownia elongata) odununun teknolojik özellikleri, KSÜ Doğa Bilimleri Dergisi, Özel Sayı, 102-108.

Çavuş, V., Ayata, Ü., (2018). Manolya ağacı, akçaağaç ve tespih ağacı odunlarında vida tutma direnci üzerine bir araştırma, Mobilya ve Ahşap Malzeme Araştırmaları Dergisi, 1(2), 94-102. DOI: 10.33725/mamad.496615.

Dinçel, K., Çelebi, N., Şanıvar, N., (1970). Ağaç Teknolojisi, Erkek Teknik Yüksek Öğretmen Okulu Yayınları, Milli Eğitim Basımevi, İstanbul, Genel: No: 292, Seri C, No: 15, 270 sayfa.

Doyle, J., Walker, J.C.F., (1984), Indentation hardness of wood, Wood and Fiber Science, 17(3), 369-376.

Dündar, T., (1997), Demirköy istranca meşeleri (Quercus hortwissiana stev.) nin teknolojik özellikleri, İstanbul Üniversitesi, Fen Bilimleri Enstitüsü, Orman Endüstri Mühendisliği Anabilim Dalı, Yüksek Lisans Tezi, İstanbul.

Govorčin, S., Sinković, T., Sedlar, T., Ištok, I., Vukadin, M., (2012). Some physical and mechanical properties of plum tree (Prunus Domestica L.), Drvna Industrija, 63(4), 291-29.

Göker, Y., As, N., Akbulut, T., Ayrılmış, N., (1999), Harnup (Ceratonia siliqua L.) odununun teknolojik özellikleri ve kullanımı, İstanbul Üniversitesi Orman Fakültesi Dergisi, Seri A, Cilt 49, Say1 2, 43-58. 
Hammond, J.J., Donnelly, E.T., Harrod, W.F., Rayner, N.A., Özden, F., (1969), A ̆gaç işleri teknolojisi, Mesleki ve Teknik Öğretim Kitapları, Editör: İrfan Zorlu, Ajans Türk Matbaacilık Sanayi, 554 sayfa.

Holmgren, H., (2000), Influence of grain angle on Brinell hardness of Scots pine (Pinus sylvestris L.), Holtz als Roh-und Werkstoff, 58: 91-95. DOI: 10.1007/s001070050392.

Jamil, A.W.M., (2016), Janka hardness rating of Malaysian timbers, Forest Research Institute Malaysia (FRIM), No: 58, ISSN: 139-258.

Kantay, R., As, N., Ünsal, Ö., (2000), Ceviz (Juglans regia L.) odununun yoğunluğu ve bazı mekanik özellikleri, Turk J Agric For, 24, 751-756.

Kiaei, M., Tajik, M., Vaysi, R., (2014), Chemical and biometrical properties of plum wood and its application in pulp and paper production, Maderas. Ciencia y Tecnología 16(3), 313-322.

Rajab, B.A., (2014), Thermal treatment of several wood species grown in Iraq, Kahramanmaraş Sütçü İmam University, Graduate School of Natural and Applied Science, Department of Forest Industry Engineering, Master Thesis, Kahramanmaraş, Turkey.

Sarıbaş, M., (2016), Ormancılık Terimler Sözlüğü, Türk Dil Kurumu Yayınları, Ankara, 676 sayfa, ISBN: 978-975-16-3199-2.

Şahin, H.İ., (2013), Isıl işlemin doğal ve plantasyon ormanlarında yetişen dişbudak (Fraxinus angustifolia Vahl.) odunlarının bazı teknolojik özelliklerine etkisi, Düzce Üniversitesi, Fen Bilimleri Enstitüsü, Doktora Tezi, Düzce.

Şahin, S., Ayata, Ü., Bal, B.C., (2019a), Karabiber ağaç türünde bazı odun-su ilişkilerinin ve 1s1 iletkenlik özelliğinin belirlenmesi, Çukurova 3. Uluslararası Yenilikçi Bilimsel Araştırmalar Kongresi, 3 - 6 Ekim, Adana, Türkiye, 431-439.

Şahin, S., Bal, B.C., Ayata, Ü., (2019b), Tespih odununda 1sı iletkenlik değeri ve bazı fiziksel özelliklerinin araştırılması, Avrasya 5. Uluslararası Uygulamalı Bilimler Kongresi, 1517 Kasım, Adana, Türkiye, 637-645.

Şanıvar, N., Zorlu, İ., (1980), Ağaçişleri Gereç Bilgisi Temel Ders Kitabı, Mesleki Ve Teknik Öğretim Kitapları, Milli Eğitim Basımevi, İstanbul, Etüd ve Programlama Dairesi Yayınlar1 No: 43, 472 sayfa.

TS 2472, (1976), Odunda, fiziksel ve mekaniksel deneyler için birim hacim ağırlığ 1 tayini, Türk Standartları Enstitüsü, Ankara.

TS 2479, (1976), Odunun statik sertliğinin tayini, Türk Standartları Enstitüsü, Ankara.

URL 1. Tespih (Melia azedarach L.) ağaç türü, https://uses.plantnetproject.org/en/Melia_azedarach_(PROSEA), (21.04.2019)

URL 2. Tespih (Melia azedarach L.) ağaç türü, https://www.woodworkerssource.com/ online_show_wood.php?wood=melia\%20azedarach, (21.04.2019)

Yuen, K.C., Muyang, K., Shang, C.Y., Mee, W.C., Jarroop, Z., Aniza, S.N., (2018), Kenafbased composite posts as alternative supports for black pepper (Piper nigrum L.), Pertanika Journal of Tropical Agricultural Science, 41(1), 163-176. 